\title{
Evaluation of Standard API Casing Connections and Parametric API Buttress Improvement by Finite Element Analysis
}

\author{
Rodrigo Rangel Porcaro ${ }^{a *}$, Luiz Cláudio Cândido ${ }^{a}$,Vicente Braz Trindade ${ }^{a}$, Geraldo Lucio de Faria ${ }^{a}$, \\ Leonardo Barbosa Godefroid ${ }^{a}$ \\ ${ }^{a}$ Rede Temática em Engenharia de Materiais - REDEMAT, Departamento de Engenharia Metalúrgica e \\ de Materiais - DEMET, Universidade Federal de Ouro Preto - UFOP, Ouro Preto, MG, Brasil
}

Received: October 9, 2015; Revised: June 6, 2016; Accepted: November 20, 2016

\begin{abstract}
Threaded and coupled connections generally present a non-uniform stress distribution, which is related to the higher stiffness of the box when compared to the pin. The non-uniform stress distribution can contribute to fatigue cracks and other failure modes in high pressure oil wells. An API 5CT P110 steel obtained from a seamless pipe was mechanically characterized. FEA models were carried out to investigate and compare two API casing connections under make-up torque and tensile efforts. A parametric study was performed using numerical models to determine the influence of some geometric features on the behavior of the API Buttress threaded connection. The API Buttress connection supported higher tensile loads than the API Short Round, however both standard connections showed high stress concentration in the last engaged thread and a non-uniform stress distribution. The manufacturing of grooves at the first and the last engaged threads proved to be an efficient way to reduce the stress concentration of Buttress casing connection and could be an alternative to the development of new products.
\end{abstract}

Keywords: Threaded Connections, Thread Parametric Study, API Thread Geometry, API 5CT Steel

\section{Introduction}

Casing strings for oil and gas exploration and production are generally formed by threads. The use of threaded connection instead of welding is justified by the major productivity and the reversibility of the threaded connections ${ }^{1}$.

Dynamic loading is common in connection service conditions. Aiming to maintain their integrity they are generally preloaded, for example, by the use of tapered threads. The combination of preload, tensile, internal and external pressure and, in some cases bending, can result in a complex stress state $e^{2,3,4}$.

Proprietary connections have been developed by companies to ensure the integrity of the strings in applications as highdeep oil wells or to improve some character of the basic API standard. The premium connections, for example, are generally developed by modifications of some geometric parameters to reduce the stress concentration factor, support higher make-up torque or ensure sealing capacity ${ }^{3-6}$.

Many researchers have been reported that the API casing connections shows a stress concentration in the region of the last engaged thread and a non-uniform stress distribution that can result in fatigue cracks and other failure modes ${ }^{2-6}$. The stress concentration is related to the higher stiffness of the coupling (box) when compared to the tube (pin) and some proprietary connections have been developed by geometric changes in the box aiming to promotes a better

* e-mail: rodrigoporcaro@yahoo.com.br stress distribution over the threads. Most of the information related to the development of proprietary connections is protected by commercial interests and are not available in the open literature. However, a review in patents show how premium connections have been developed ${ }^{6-10}$.

In this work, a steel API 5CT grade P110 obtained from a seamless pipe was characterized by mechanical tests. The properties of the steel were used to simulate two types of API threaded and coupled connections, API Short Round and API Buttress, both with diameter 13 3/8 in. Finite Element Analysis was used to simulate the problem in the software Ansys ${ }^{\circledR}$ Workbench ${ }^{\circledR}$ version 14.5. Both connections were submitted to tensile stresses and the jump-out (which is the separation tendency between pin and box) was evaluated, as well as the stress concentration factor.

A parametric study was applied to the base connection API Buttress to evaluate how some geometric modifications can influence the connection integrity and the stress concentration factor. This parametric study was based in a patent review ${ }^{6-10}$.

The obtained results help to understand how proprietary casing connections are developed and why the Standard API connections are not applied in high pressure oil wells and deep water. Besides, the optimized load distribution obtained in a grooved API Buttress connection has never been related in the technical literature and could be an alternative to the development of new products. 


\section{Materials and Methods}

An API 5CT grade P110 steel from a seamless pipe of 13 3/8 in. diameter and $12.19 \mathrm{~mm}$ wall thickness was firstly mechanically characterized. Tensile and Charpy impact tests were performed according to API 5CT ${ }^{11}$ and ASTM A $370^{12}$ standards. Six samples were used in tensile and nine in impact tests.

Chemical analysis was performed on the steel to assure the requirements of the API 5CT (Table 1).

Threaded and coupled connections were generated as CAD models on the Ansys ${ }^{\circledR}$ Design ${ }^{\circledR}$ Modeler $^{\circledR}$ based on API 5B standard for Short Round and Buttress connections types $^{13}$. The models were $2 \mathrm{D}$ axisymmetric, as can be seen in Figure 1. Figure 1-a shows an API Casing connection model with symmetry related to the coupling middle and the pipe axis, Figure 1-b shows a resultant 2D axisymmetric model.

All geometric parameters used in the API Buttress and API Short Round connections were based on the API 5B and API 5CT specifications. The pipe length was the same suggested by API $5 \mathrm{C} 5^{14}$ and assure that border effects are negligible.

The modeling of the steel plasticity was possible by the application of the multilinear isotropic hardening model, available in Ansys software. The obtained parameters in the tensile test were converted to truly stress-strain curve, as suggested in the Ansys reference documentation ${ }^{15}$, and applied as boundary condition.

Aiming to simulate the thread contacts, a Coulombian friction coefficient $\mu=0.12$ was used. This value was defined in accordance with a preview work ${ }^{2}$.

High order elements were used to mesh the model and a mesh refinement evaluation was performed. Figure 2 presents the obtained discretization for the proposed system. The global mesh size is $3 \mathrm{~mm}$ and the refinement applied to the thread flanks is indicated in Table 2. The structural error stabilization and the stress concentration factor at the last engaged thread of a Short Round connection were used to define the mesh size refinement.

As can be seen in Table 2, a local refinement of $0.08 \mathrm{~mm}$ is enough to the problem, because the structural error was stable and the stress concentration factor is close to the reported in the literature for this connection model ${ }^{2}$.

The structural simulation was carried out in two different stages: (i) make-up torque, (ii) make-up plus axial tensile stress at the connection. The make-up torque that results of the tapered threads cannot be modeled directly in the $2 \mathrm{D}$ models. The thick cylinder theory with an initial interference fit was used in this work, as shown in Figure 3. In this approach, an initial interference between the threads of pin and box as a function of make-up turns was solved by the software in a primary stage. Many researchers have shown that this approach results in a stress distribution over the threads close to that obtained in physical models ${ }^{2,16,17}$. The initial interference $\delta$ (or radial overlap) value was calculated by the Equation $1^{16}$, and the parameters were obtained for the API 5B standard.

$$
\delta=N P T / 2
$$

Where $N$ is the tighten cycle, $P$ is the thread pit and $T$ is the taper of the conic threaded connections.

Table 3 presents make-up torques evaluated in both API connections (input data in the current models) and presents the evaluated simulation outputs.

The calculus of the stress distribution in the connections under tractive conditions was the second stage of the simulations, as shown in Figure 4. At this simulation stage, the make-up torque was considered simultaneously with a crescent tractive stress applied to the pipe (point B in Figure 4). The axial displacement of all nodes are zero on the middle symmetry plane of the coupling (point A in Figure 4) and their radial displacements are free.

The values of tensile stress simulated in both connections are shown in Table 4.

After the standard API connection evaluations, a parametric study based on a patent review was performed. API Buttress connection was chosen as base to the parametric study and the proposed modifications were based on patents that aim to obtain a better stress distribution in tubular threaded connections. The first modification was the decreasing of box wall thickness in order to decrease its stiffness, as Figure 5 presents.

The second modification was applied on the threads and was based in a patent that was not applied to any commercial product yet ${ }^{10}$. The patent claims that an additional groove in the threads crests at the first and last engaged threads regions reduces the thread stiffness, transferring partially the load to the subsequent threads, improving the load distribution over the connection. In this study, the grooves presence was simulated in the Buttress connection and the obtained results were compared to the standardized API connection in order to evaluate its performance.

\section{Results and Discussion}

The results of tensile and Charpy impact tests of the API 5CT grade P110 steel are presented in Table 5. The obtained

Table 1: Chemical specifications of the API 5CT grade P110 steel(wt $\%)$.

\begin{tabular}{|c|c|c|c|c|c|c|c|c|c|c|c|c|c|}
\hline \multirow{2}{*}{ Grade } & \multicolumn{2}{|c|}{$\mathrm{C}$} & \multicolumn{2}{|c|}{$\mathrm{Mn}$} & \multicolumn{2}{|c|}{ Mo } & \multicolumn{2}{|c|}{$\mathrm{Cr}$} & \multirow{2}{*}{$\begin{array}{c}\mathrm{Ni} \\
\text { Max. }\end{array}$} & \multirow{2}{*}{$\begin{array}{c}\mathrm{Cu} \\
\text { Max. }\end{array}$} & \multirow{2}{*}{$\begin{array}{c}\mathrm{P} \\
\text { Max. }\end{array}$} & \multirow{2}{*}{$\begin{array}{c}\text { S } \\
\text { Max. }\end{array}$} & \multirow{2}{*}{$\begin{array}{c}\mathrm{Si} \\
\mathrm{Max} .\end{array}$} \\
\hline & Min. & Max. & Min. & Max. & Min. & Max. & Min. & Max. & & & & & \\
\hline P110 & - & - & - & - & - & - & - & - & - & - & $0.030^{\mathrm{e}}$ & $0.030^{\mathrm{e}}$ & - \\
\hline
\end{tabular}

${ }^{\mathrm{e}}$ For EW Grade P110, the phosphorus content shall be $0.020 \%$ maximum and the sulfur content $0.010 \%$ maximum. 


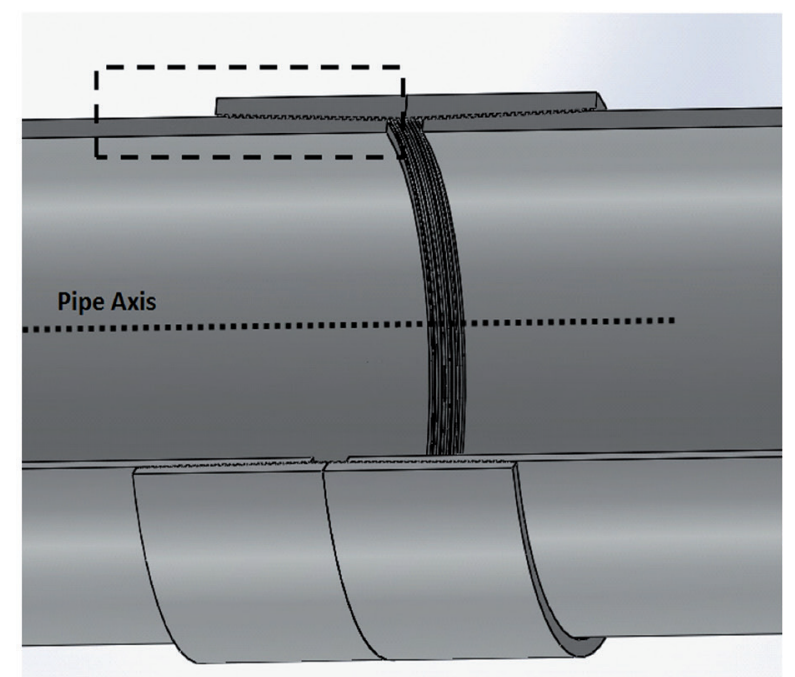

a) Axisymmetric condition

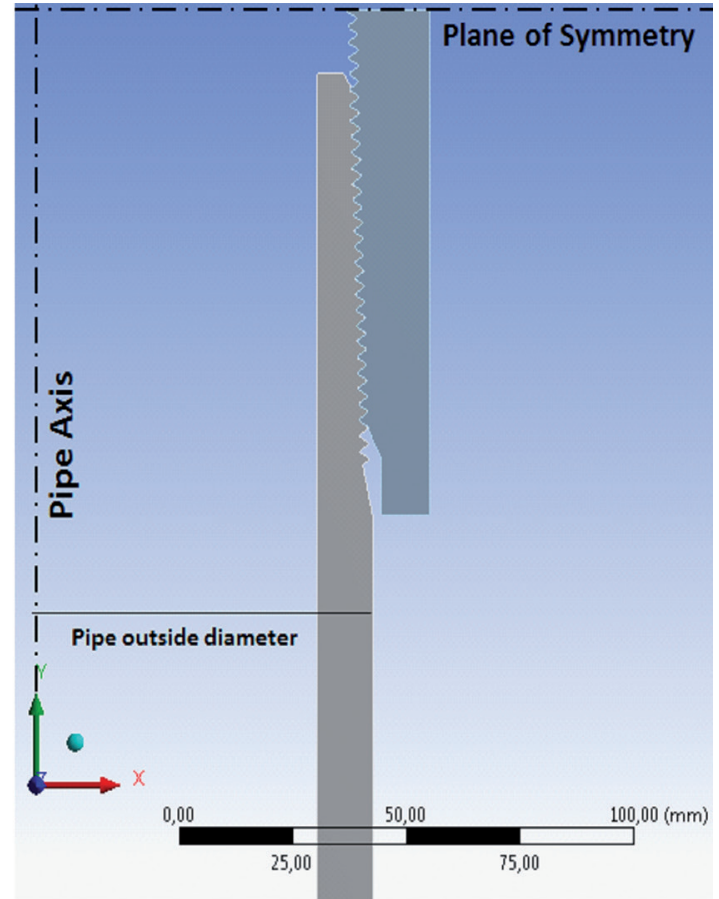

b) A Short Round 2D model

Figure 1: CAD models of the treaded connections (a) API Casing connection and symmetry related to the coupling middle and the pipe axis; (b) 2D axisymmetric model.

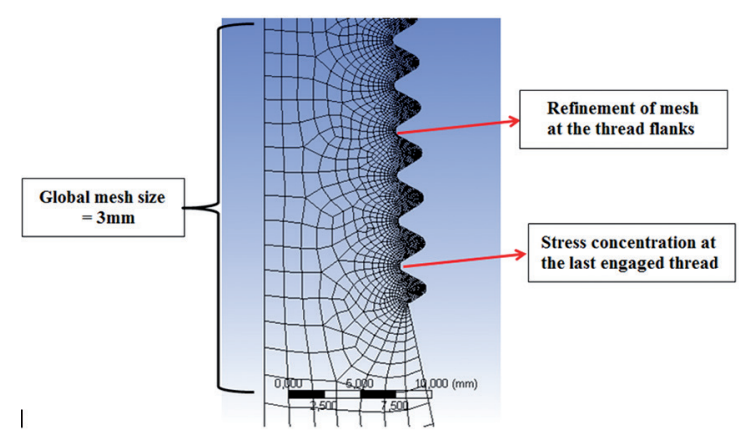

Figure 2: Mesh refinement study.

Table 2: Mesh refinement study.

\begin{tabular}{lccc}
\hline $\begin{array}{l}\text { Local } \\
\text { refinement } \\
(\mathrm{mm})\end{array}$ & $\begin{array}{c}\text { Number } \\
\text { of } \\
\text { elements }\end{array}$ & $\begin{array}{c}\text { Maximum } \\
\text { structural } \\
\text { error }(\mathrm{mJ})\end{array}$ & $\begin{array}{c}\text { Maximum stress } \\
\text { concentration (Tensile }= \\
100 \mathrm{MPa})\end{array}$ \\
\hline 0.05 & 50391 & 2.32 & 7.08 \\
0.08 & 28401 & 2.74 & 7.05 \\
0.1 & 21395 & 2.85 & 6.95 \\
0.2 & 10239 & 10.84 & 6.88 \\
0.3 & 7168 & 23.93 & 6.46 \\
\hline
\end{tabular}

values in mechanical tests and in chemical analysis were in accordance with API 5CT ranges for the P110 steel grade.

The jump-out of the connections is shown in Figure 6-a and Figure 6-b as functions of make-up torque and tensile stress, for API Short Round and API Buttress, respectively.

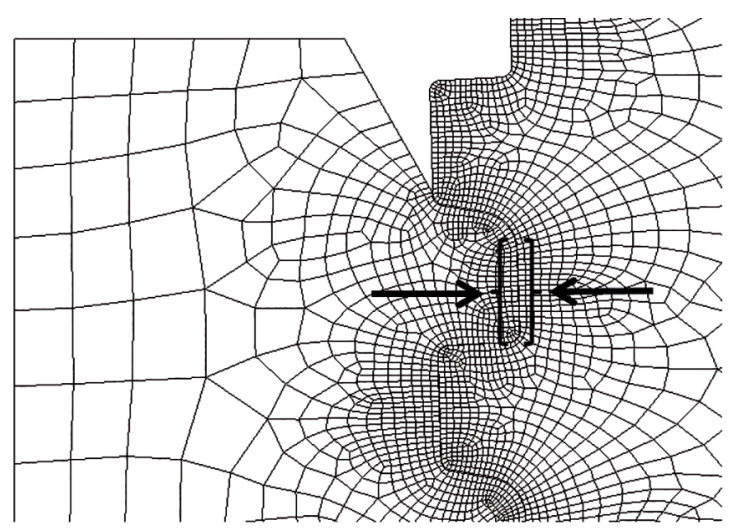

Figure 3: Initial interference fit related to make-up torque of the tapered threads.

The jump-out is a failure mode of the threaded connections with the formation of a gap between the thread flanks and can promotes the total separation of the casing string. As can be seen in Figure 6, the make-up torque had great influence in the resistance to jump-out of the standard connections. It is also possible to observe that the API Buttress connection had higher jump-out resistance than API Short Round. A previous work ${ }^{18}$ also found that the API Buttress casing connection has higher jump-out resistance than API Round when subjected to axial tensile stress.

Assanelli et al. ${ }^{19}$ used finite element analysis to evaluate the influence of make-up torque in the jump-out load of a 
Table 3: Make-up torque evaluated in the API connections.

\begin{tabular}{lccccc}
\hline Connection & \multicolumn{3}{c}{ Make-up (Turns) } & Comparative answers or Simulation Output Values \\
\hline Short Round & No torque & 1.5 & 2.5 & 3.5 & $\begin{array}{c}\text { Stress distribution } \\
\text { Buttress }\end{array}$ \\
No torque & Min. ${ }^{\text {a) }}$ & - & Máx. ${ }^{\text {a) }}$ & $\begin{array}{c}\text { Stress concentration } \\
\text { Jump-out }\end{array}$ \\
\hline
\end{tabular}

a) For the API Buttress connection, the face of the coupling advances to one turn of the base of the triangle stamp for minimum make-up and to the apex of the triangle stamp for maximum make-up.

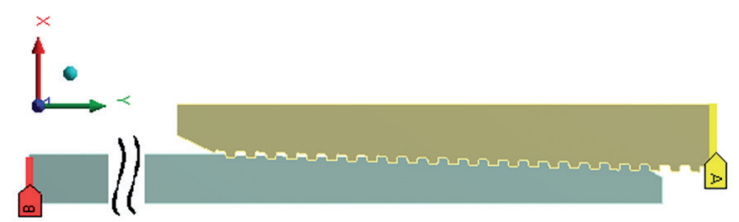

Figure 4: Axisymmetric condition and the boundary conditions of the second stage of the simulation: make-up torque plus crescent tensile stress applied in B. Point A is the symmetry plane with axial displacement set to zero (Y direction).

Table 4: Tensile stresses applied to the connections and evaluated output values.

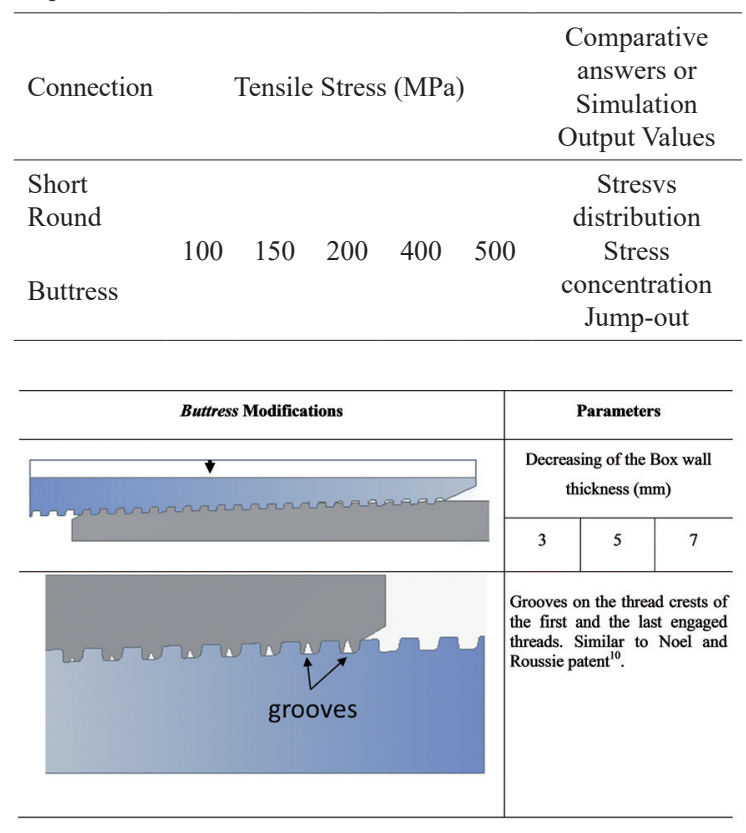

Figure 5: Geometrical modifications used in the parametric study.
$5 \frac{1}{2}$ in., J-55 API 8-Round casing connection. The authors reported an increase in $20 \%$ of axial tensile load that promoted jump-out of the connection, when the make-up torque increased from two to four turns.

The results show the importance of considering makeup in numerical models of tapered threaded and coupled connections.

The distribution of load flank reaction over the threads in the Short Round API connection is shown in Figure 7 as an answer of tensile stress and maximum make-up torque. As can be seen, the load distribution is non-uniform and the last engaged thread (flank 1) concentrated load and can be a fatigue cracking site if the connection is subjected to cyclic loading. The result of load distribution in the API Round connection was very similar to a previous numerical work ${ }^{16}$, in which the authors also found that the three first load flanks concentrates most of the load when an 9 5/8 in. P110 API Round connection was subjected to axial tensile stress.

The distribution of reaction load over the load flanks of the Buttress connection is shown in Figure 8 as an answer of tensile stress and maximum make-up torque. As can be seen, the load of the API Buttress connection is non-uniform, but the load profile is better than that seen in the Short Round connection. The load distribution over the flanks of the Buttress connection was similar to reported in ${ }^{20}$ for a premium connection with Buttress threads $5 \frac{1}{2}$ in., API 5CT L80, including the small load supported by the central flanks and higher load over the first and last engaged threads.

The results of jump-out and load distribution over the threads help to explain why the API Buttress connection is applied in severe conditions in place of the API Short Round $^{1,4,18}$.

Table 5: Mechanical properties of API 5CT grade P110 steel.

\begin{tabular}{cccccc}
\hline & $\begin{array}{c}\text { Tensile Tests } \\
\text { Sample }\end{array}$ & Yield Strenght (MPa) & Tensile Strenght (MPa) & \multicolumn{3}{c}{ Charpy Impact Tests } \\
Individual values at $0^{\circ} \mathrm{C}(\mathrm{J})$
\end{tabular}




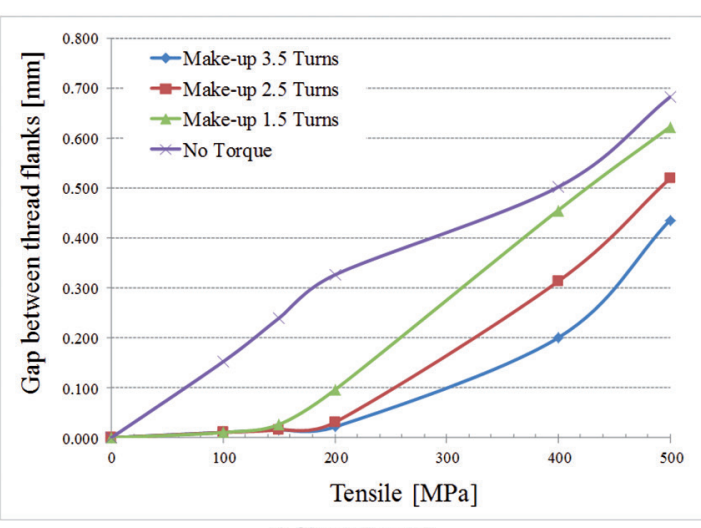

a) Short Round

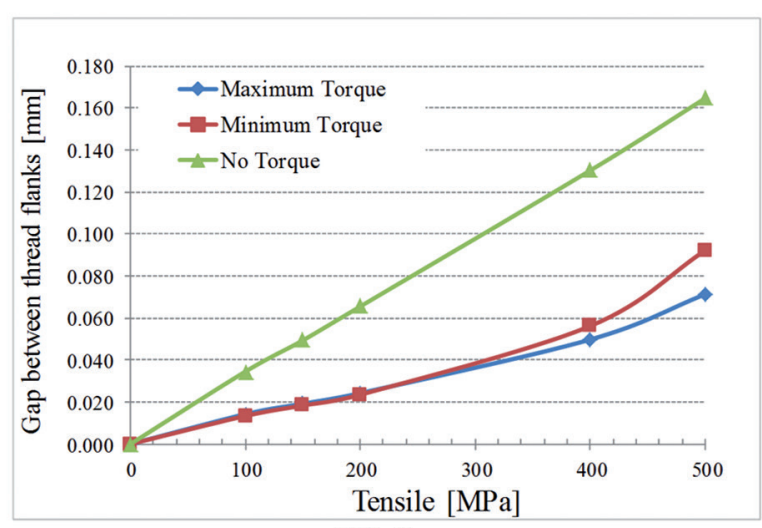

b) Buttress

Figure 6: Results of Jump-out tendency of API standard threaded connections as function of make-up torque and tensile stress.

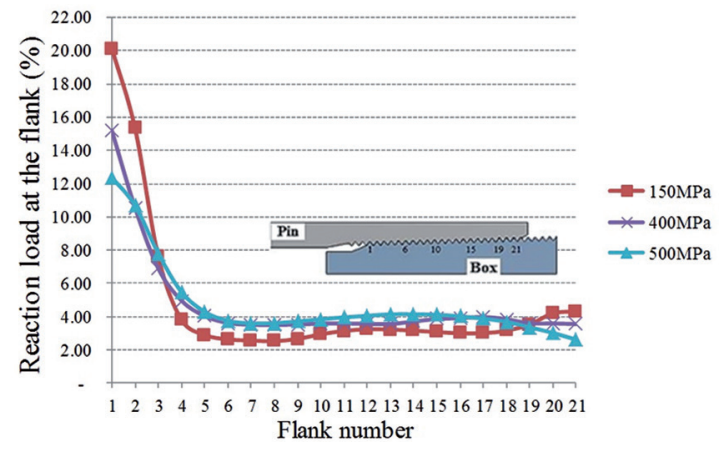

Figure 7: Results of load distribution over the flanks of API Short Round casing connection.

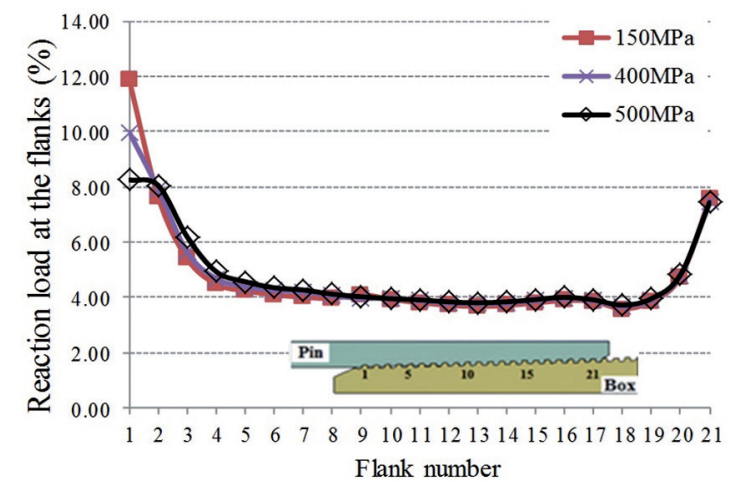

Figure 8: Results of load distribution over the flanks of API Buttress casing connection.

The axial stress in the API connections when subjected to $500 \mathrm{MPa}$ tensile stress and maximum make-up torque is shown in Figure 9. The analysis of the results shown in Figure 9 leads to conclusion that the API Buttress connection has a better stress distribution profile than the API Short Round, but both connections have a high stress concentration in the region of the last engaged thread.

The stress concentration obtained as maximum axial tensile divided by applied tensile stress in both Standard API connections when subjected to different tensile is shown in Table 6. The API Buttress connection shows lower stress concentration than the API Short Round, which is attributed to the trapezoidal shape of the API Buttress thread and its limited thread height ${ }^{2}$.

The lower jump-out resistance of the API Short Round and the higher stress concentration is related to its triangular thread form (that develops radial forces when subjected to tensile stress) and its reduced cross section of the unengaged thread section of the $\operatorname{pin}^{2,18}$.

\subsection{Parametric Study}

The results of the reaction load distribution over the thread flanks of a Standard API Buttress connection is compared to modified connections with box wall thickness reduction in Figure 10-a, the boundary condition is the maximum torque plus 200MPa tensile stress. As can be seen, the box wall thickness reduction was inefficient in reducing stress concentration, once the stress concentration was just switched from the two first threads of the pin to the three last, while the central threads (threads 4 to 19) still support low loads.

Another result that confirms the inefficiency of the box wall reduction is the impact in the jump-out resistance of the modified connections showed in Figure 10-b. The bigger the wall thickness reduction, the smaller the jump-out resistance of the modified Buttress connection.

The results of reaction load distribution at the thread flanks, obtained by the model with grooves in the first and in the last engaged threads, are shown in Figure 11. A comparison between standardized API Buttress connection when subjected to maximum make-up torque and 200MPa tensile stress and the proposed connection in the same condition are also presented. The proposed geometric modification was effective in promoting a better load distribution over the threads: (i) reduction from $12 \%$ to $7 \%$ of the load supported by the thread 1; (ii) increasing of the load supported by the intermediate threads (flanks 4 to 20); (iii) lowering the load supported by the last flank. So, this geometric modification 

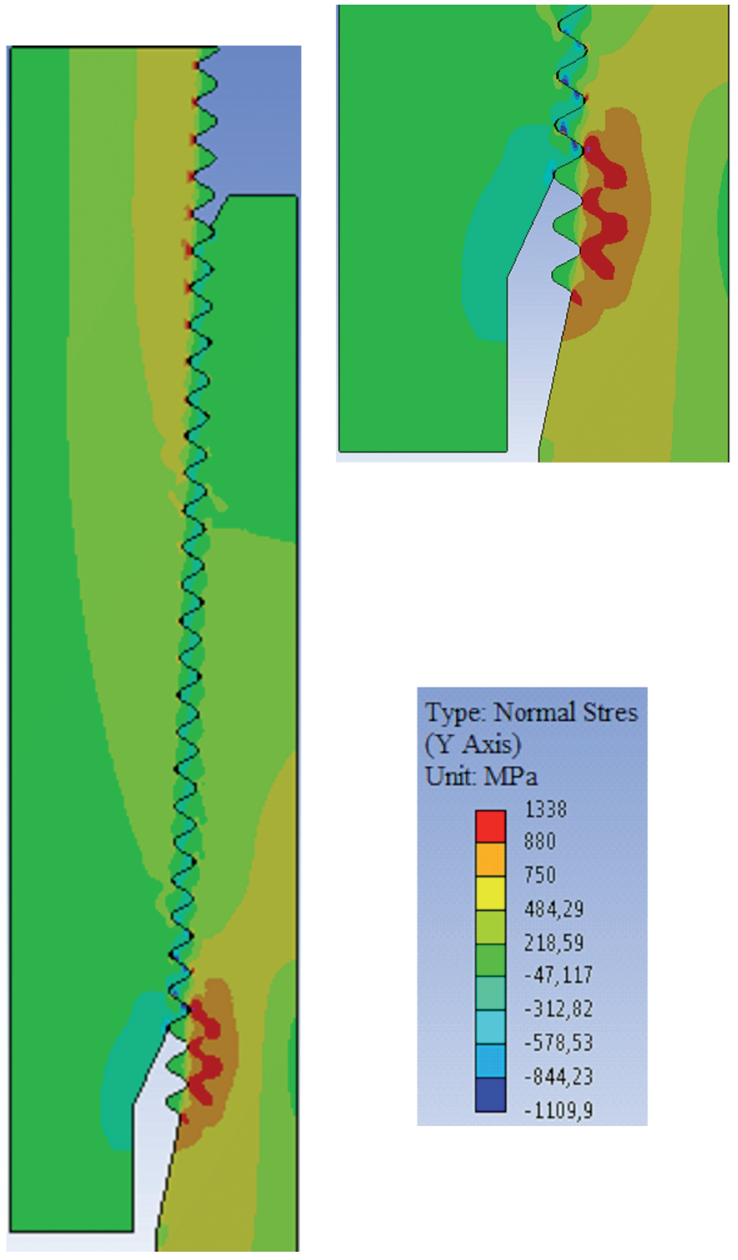

\section{(a) API Short Round}

\section{(b) Detail Short Round and} color scale
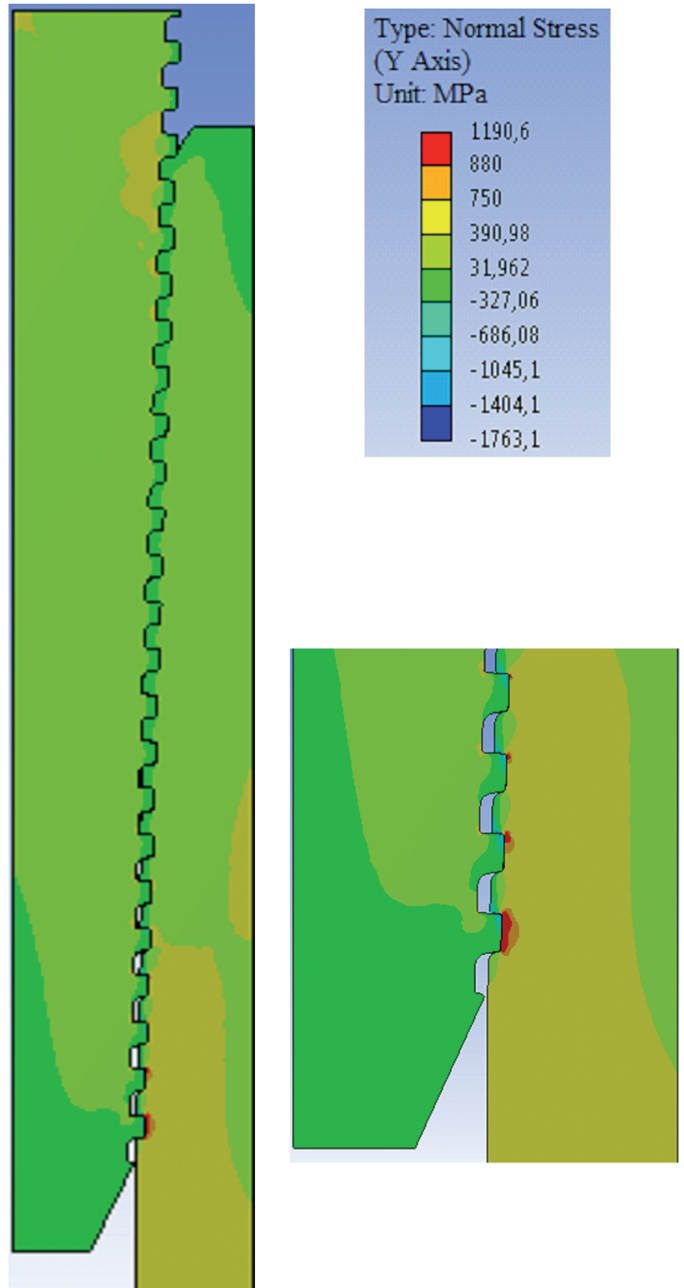

(c) API Buttress

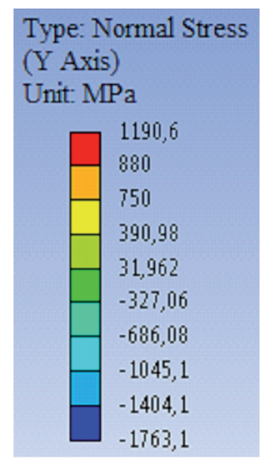

(d) Detail Buttress and color scale

Figure 9: Axial stress distribution on the API connections as a result of maximum make-up torque and 500MPa tensile.

Table 6: Stress concentration in API Short Round and Buttress obtained in different tensile stress.

\begin{tabular}{lccccc}
\hline Connection & \multicolumn{5}{c}{ Tensile stress (MPa) } \\
\cline { 2 - 6 } & 100 & 150 & 200 & 400 & 500 \\
\hline Short Round & 7.73 & 6.99 & Axial stress concentration (-) \\
Buttress & 6.90 & 6.46 & 5.70 & 3.35 & 2.95 \\
\hline
\end{tabular}

resulted in a better load distribution over the connection without significant lost in jump-out resistance (Figure 11-b).

The improvement of the load distribution over the threads in the grooved modified API Buttress, with no influence in the jump-out resistance, are in accordance with the original and no applied patent ${ }^{10}$ and could be a good alternative to the development of new products.

\section{Conclusions}

- The make-up torque is an important variable to be considered in the modeling of tapered threaded connections, once the torque had great influence in the jump-out results. Besides, the standard API Buttress has higher resistance to jump-out than the API Short Round. 


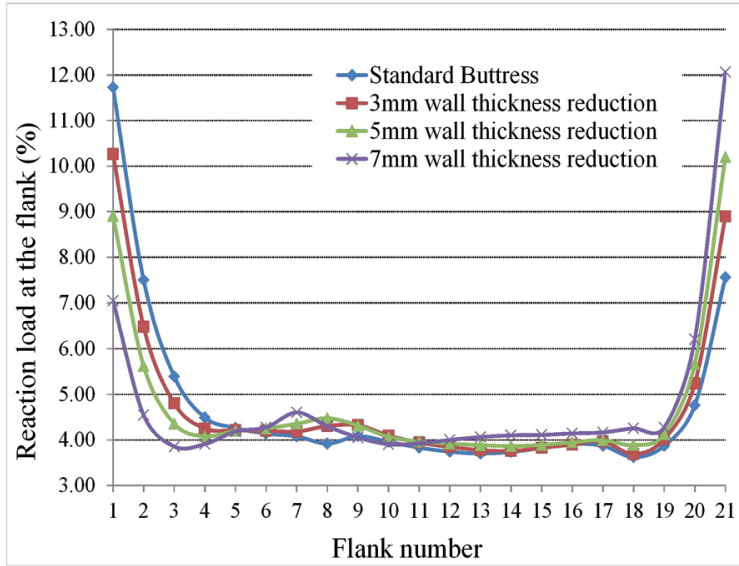

a) Distribution of reaction load at the threads

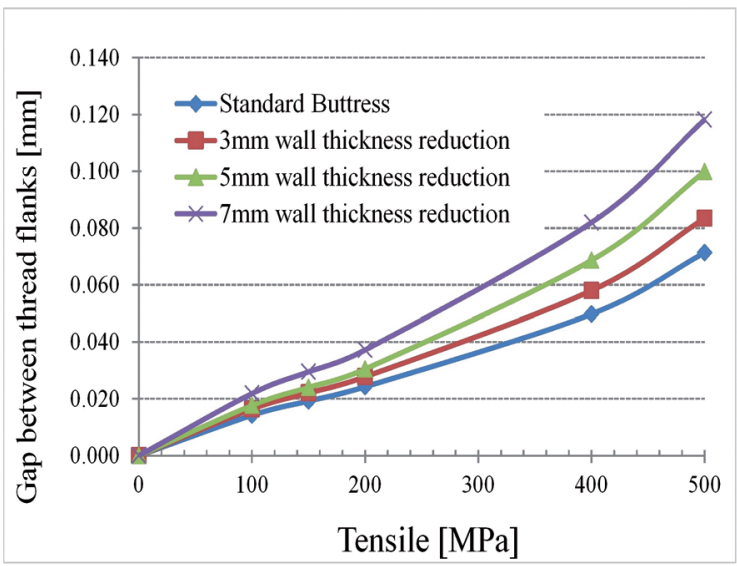

b) Jump-out tendency of the connections

Figure 10: Results of reaction load distribution in standard and modified Buttress connections and jump-out tendency. Boundary conditions: a) Maximum make-up torque plus 200MPa tensile stress; b) Maximum make-up torque plus crescent tensile stress.

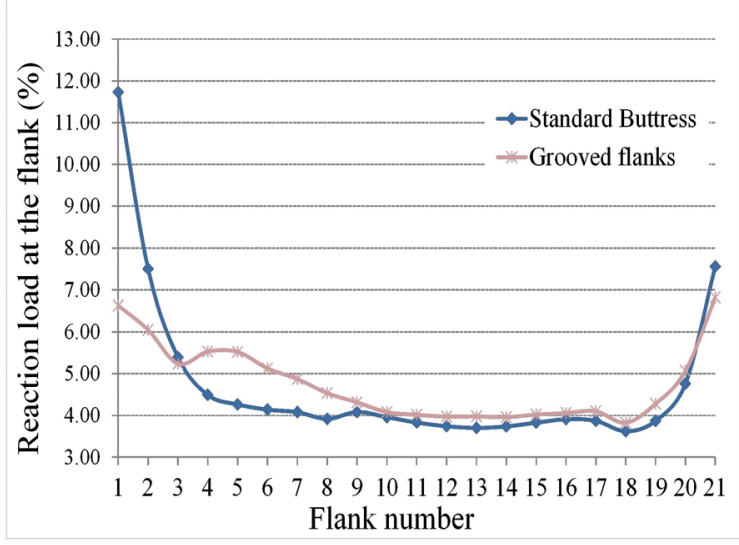

a) Reaction load distribution over the thread flanks

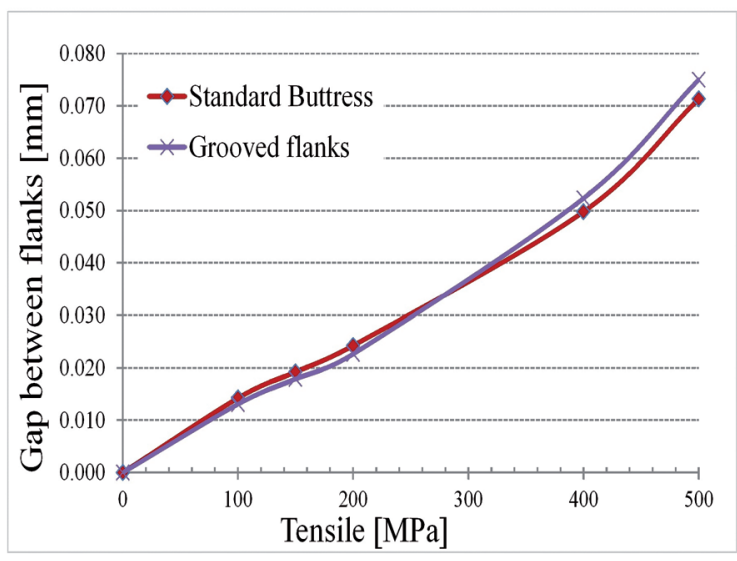

b) Jump-out tendency of the connections

Figure 11: Results of reaction load distribution and jump-out of the modified (grooved) connection compared to the standard API Buttress connection. Boundary conditions: a) maximum make-up torque plus 200MPa tensile stress; b) maximum make-up torque plus crescent tensile stress.

- Both standard API casing connections have non uniform load distribution over the threads, but the stress concentration of the API Short Round is higher than the API Buttress.

- The reduction of wall thickness of the box of API Buttress connection in order to minimize its stiffness was inefficient in decreasing stress concentration, once the stress concentration was not reduced and the jump-out tendency increased.

- The modification of the API Buttress casing connection by the confection of grooves in the last and first engaged threads was effective in promoting better load distribution over the thread flanks and reducing the stress concentration factor. The simulated grooves did not change the jump-out resistance of the connection and could be an alternative to the development of improved Buttress connections.

\section{Acknowledgements}

The authors would like to thank the Brazilian Research Agencies CAPES and CNPq for the financial support and the scholarship.

\section{References}

1. Bourgoyne AT, Chenevert ME, Millheim K, Young FS Jr. Applied Drilling Engineering. SPE Textbook Series. Vol. 2. Richardson: Society of Petroleum Engineers; 1986. 502 p.

2. van Wittenberghe J. Experimental analysis and modelling of the fatigue behaviour of threaded pipe connections. [Dissertation]. Ghent: Ghent University; 2011. 287 p.

3. Yamamoto K, Kobayashi K, Maguchi T, Ueno K. Stress Analysis of Premium Threaded Connection "FOX" by Finite Element Method. Kawasaki Steel Giho. 1989;21(3):202-207. 
4. Galle T, De Waele W, De Baets P, van Wittenberghe J. Influence of Design Features on the Structural Integrity of Threaded Pipe Connections. Sustainable Construction and Design. 2011;2(2):237-245.

5. Galle T, van Wittenberghe J, Camelia Jula F, De Waele W, De Baets P. Effect of Load Flank Angle Modifications on the Structural Integrity of Buttress Threaded Connections. Sustainable Construction and Design. 2013;4(1):7p.

6. van Wittenberghe J, De Baets P, De Waele W, Galle T, Bui TT, De Roeck G. Design Characteristics that Improve the Fatigue Life of Threaded Pipe Connections. Sustainable Construction and Design. 2011;2(2):334-341.

7. Bodine AG, inventor; Bodine AG, assignee. Sonic well pump tubing string. United States patent US 2992613. 1961 Jul 18.

8. De Lange RW, Evans ME, inventors; Grant Prideco LP, assignee. Threaded and coupled connection for improved fatigue resistance. United States patent US 6609735 B1. 2003 Ago 26.

9. Verdillon L, inventor; Vallourec Mannesmann Oil and Gas France, Sumitomo Metal Industries Ltd, assignee. Fatigue-resistant threaded bevelled tubular element. United States patent US 6752436B1. 2004 Jun 22.

10. Noel T, Roussie G, inventors; Vallourec Mannesmann Oil and Gas France, Sumitomo Metal Industries Ltd, assignee. Fatigueresistant threaded component for a tubular threaded joint. United States patent, US 7513534B2. 2009 Apr 7.

11. American Petroleum Institute. Specification for Casing and Tubing. API Specification 5CT. $9^{\text {th }}$ ed. Washington: American Petroleum Institute; 2011.
12. ASTM International. ASTM A 370 - Standard Test Methods and Definitions for Mechanical Testing of Steel Products. West Conshohocken: ASTM International; 2012.

13. American Petroleum Institute. Specification for Threading, Gauging and Thread Inspection of Casing, Tubing, and Line Pipe Threads. API Specification $5 B .15^{\text {th }}$ ed. Washington: American Petroleum Institute; 2008.

14. American Petroleum Institute. Recommended Practice for Evaluation Procedures for Casing and Tubing Connections. API Specification 5C5. $2^{\text {nd }}$ ed. Washington: American Petroleum Institute; 1996.

15. ANSYS. Getting Started with ANSYS Workbench - ANSYS Release 11.0. Canonsburg: ANSYS; 2007.

16. Chen S, Li Q, Zhang Yi, Qi A. Finite element analysis of tooth load distribution on P-110S conic threaded connections. International Journal of Pressure Vessels and Piping. 2011;88(2-3):88-93.

17. Dvorkin EN, Toscano RG. Finite element models in the steel industry. Part II: analyses of tubular products performance. Computers \& Structures. 2003;81(8-11):575-594.

18. Xie J, Tao G. Analysis of Casing Connections Subjected to Thermal Cycle Loading. In: 2010 Simulia Customer Conference; 2010 May 25-27; Providence, Rhode Island, USA.

19. Assanelli AP, Xu Q, Benedetto F, Johnson DH, Dvorkin EN. Numerical/Experimental Analysis of an API 8-Round Connection. Journal of Energy Resourches Technology. 1997;119(2):81-88.

20. Hirano Y, Maguchi T, Kobayashi K, Yamamoto K, Ueno K, Duxbury JK. Development of Premium Threaded Connection "FOX". Kawasaki Steel Technical Report. 1988;19:23-29. 